\title{
SUPRASCAPULAR NOTCH IN HUMAN SCAPULA: A MORPHOMETRIC
} STUDY

\author{
Rakshitha. ${ }^{1}$, Komala. $\mathbf{N}{ }^{* 2}$.
}

${ }^{1}$ III Year MBBS, Undergraduate, Ramaiah Medical College, Bangalore, Karnataka, India.

${ }^{* 2}$ Associate Professor, Department of Anatomy, Ramaiah Medical College, Bangalore, Karnataka, India.

\section{ABSTRACT}

Introduction: Suprascapular notch is a depression on the lateral one third of the superior border of the scapula. Suprascapular nerve passes through this notch. The shape of this suprascapular notch can vary among individuals. Various shapes and sizes of the notch and ossified superior transverse scapular ligament can compress the suprascapular nerve leading to entrapment syndromes. Hence the study of morphometry of the notch is important to diagnose and treat such entrapment syndromes.

Materials and Methods: 58 dried human scapulas were used for the study. The morphology of the suprascapular notch was studied. Presence and absence of the notch was observed. Type of notch was assessed based on the its shape according to Rengachery's classification. The superior transverse diameter, middle transverse diameter, maximum depth of the notch, and the distance between the posterior glenoid rim and the notch was measured.

Results: Type II and type III notches are common in Indian population. Type II notch has larger diameters and greater depth, while type IV has the least diameters and depth. Type V and VI notches are more prone for suprascapular nerve entrapment due to ossification of superior transverse scapular ligament.

Conclusion: Knowledge of different types of notches and its measurements are very helpful in diagnosis and management of cases with shoulder pain due to suprascapular nerve entrapment and also while administering suprascapular nerve blocks for the surgeries involving the shoulder.

KEY WORDS: Suprascapular Nerve, Suprascapular Notch, Superior Transverse Scapular Ligament, Suprascapular Nerve Entrapment Syndromes.

Address for Correspondence: Dr. Komala. N, Associate Professor, Department of Anatomy, Ramaiah Medical College, Bangalore, Karnataka, India. E-Mail: komas2001@yahoo.com

Access this Article online

Quick Response code

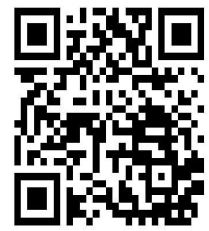

DOI: $10.16965 /$ ijar.2017.479

Journal Information

\section{International Journal of Anatomy and Research}

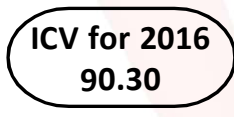

ISSN (E) 2321-4287 | ISSN (P) 2321-8967

https://www.ijmhr.org/ijar.htm

DoI-Prefix: https://dx.doi.org/10.16965/ijar

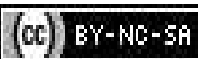

\section{Article Information}

Received: 22 Oct 2017

Peer Review: 23 Oct 2017

Revised: None
Accepted: 01 Dec 2017
Published (O): 05 Jan 2018
Published (P): 05 Jan 2018

\section{INTRODUCTION}

Suprascapular notch is a depression on the lateral one third of the superior border of the scapula[Fig-1]. Suprascapular nerve, arising from the superior trunk of brachial plexus traverses through this notch, and passes between the root of spine of scapula and the glenoid rim innervating the supraspinatus and infraspinatus muscles [1].

The shape of this suprascapular notch can vary among individuals. The various shapes and sizes of the suprascapular notch is one of the important considerations for the nerve entrapment. Sometimes, the superior transverse scapular ligament which is attached to the superior borders of the notch can be partially or completely ossified giving rise to a foramen. In such cases the chances of nerve entrapment are high and removal of the ossified ligament has provided great relief of pain in the affected patients $[2,3]$. 
Suprascapular nerve is the nerve mostly involved in Parsonage Turner Syndrome wherein the patients mainly present with severe shoulder pain followed by numbness and weakness. Hence while evaluating such cases of shoulder pain, suprascapular nerve pathologies should be kept in mind as $\mathrm{C} 5$ and $\mathrm{C} 6$ roots are mainly involved $[4,5]$. Suprascapular nerve block is given in many upper limb orthopedic surgeries. Hence the present study will be helpful to clinicians while evaluating the cases of shoulder pain.

The aim of the present study is to study the morphology of the suprascapular notch and to discuss the significance of the shape of the notch with respect to suprascapular nerve injuries.

Fig. 1: Shows suprascapular notch

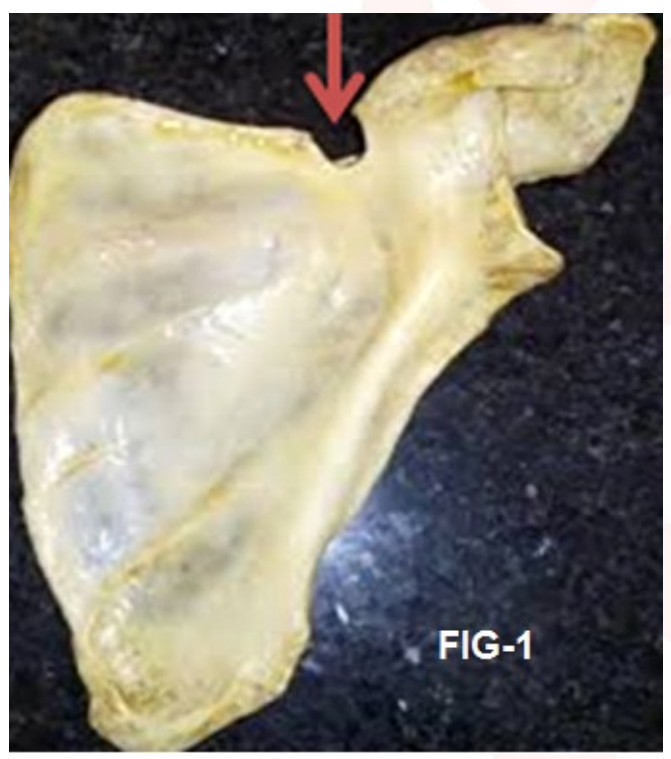

\section{MATERIALS AND METHODS}

Study Design: The present study was a prospective study which was conducted from November, 2016 - July, 2017. A total of 58 dried human scapula present in the department of Anatomy, Ramaiah Medical College, Bangalore were included in the study. The defective and broken scapula were excluded.

The morphology of the notch was studied. Presence and absence of the notch was observed. Type of notch was assessed based on the its shape according to Rengachery's classification [Fig 3-4]. The Superior transverse diameter (STD), Middle transverse diameter (MTD), Maximum depth of the notch, and the Distance between the posterior glenoid rim and the notch was measured using digital Vernier calipers[Fig-2].
All measurements are tabulated and mean values of the same are taken. Descriptive statistics of types of notches are analyzed and summarized in terms of percentages.

Fig. 2: Shows various morphometric measurements of the suprascapular notch.

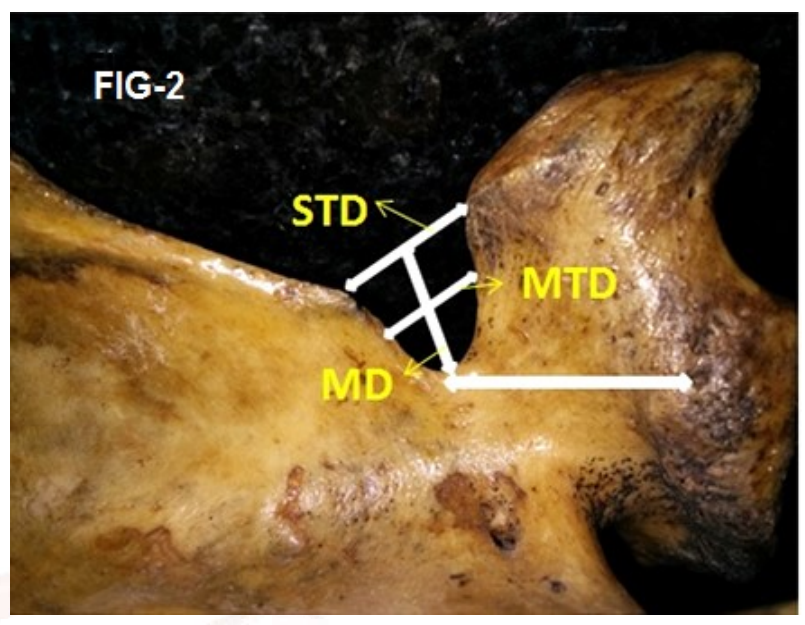

Fig. 3A: Shows TYPE-I notch - absence of notch.

Fig. 3B: Shows TYPE-II notch - wide V shaped.

Fig. 3C: Shows TYPE-III notch - symmetric U shaped.

Fig. 3D: Shows TYPE-IV notch - narrow V shaped.
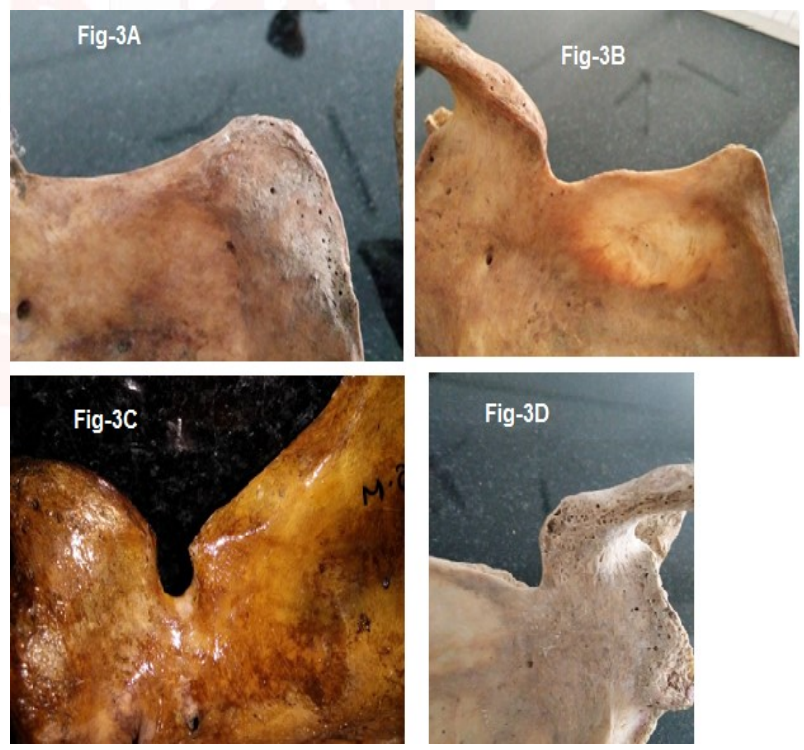

Fig. 4A: Shows TYPE -V notch - partially ossified transverse superior scapular ligament.

Fig. 4B: Shows TYPE - VI notch - completely ossified transverse superior scapular ligament.
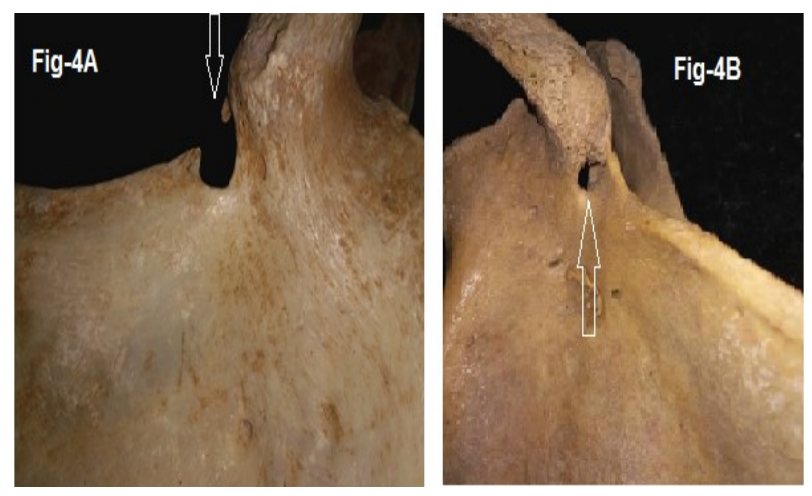


\section{RESULTS}

Table 1: Incidence of different types of suprascapular notches.

\begin{tabular}{|c|c|c|}
\hline Type of Notch & Incidence & Frequency \\
\hline I & 11 & $18.96 \%$ \\
\hline II & 20 & $34.48 \%$ \\
\hline III & 18 & $31.03 \%$ \\
\hline IV & 4 & $6.90 \%$ \\
\hline V & 4 & $6.90 \%$ \\
\hline VI & 2 & $3.45 \%$ \\
\hline
\end{tabular}

Table 2: Morphometric measurements of the different types of suprascapular notches.

\begin{tabular}{|c|c|c|c|c|c|c|}
\hline Measurements in mm & Type I & Type II & Type III & Type IV & Type V & Type VI \\
\hline Mean STD & - & $9.68 \pm 2.5$ & $9.41 \pm 2.70$ & $6 \pm 1.95$ & $9.11 \pm 2.51$ & - \\
\hline Mean MTD & - & $6.85 \pm 1.9$ & $6.55 \pm 1.97$ & $3.37 \pm 0.90$ & $6.13 \pm 1.59$ & - \\
\hline Mean max. Depth & - & $4.12 \pm 1.99$ & $4.14 \pm 1.96$ & $2.62 \pm 1.47$ & $4.04 \pm 1.87$ & - \\
\hline $\begin{array}{c}\text { Mean distance } \\
\text { between posterior } \\
\text { glenoid rim \& notch }\end{array}$ & - & $21.4 \pm 2.01$ & $21.09 \pm 2.35$ & $19.24 \pm 4.78$ & $21.12 \pm 1.97$ & - \\
\hline
\end{tabular}

In our present study of 58 scapulas, we can infer that type II and type III notches are common in Indian population [Table-1]. STD and MTD of the type II notch is greater than that of the other notches; that of type IV notch is the least. Maximum depth of the type II and type III notches is greater than the other types of notch whereas maximum depth of type IV notch is the least [Table-2]. Thus, from all these observations it can be inferred that, type II notch has larger diameters and greater depth, while type IV has least depth and diameters making the notch very narrow and hence predisposing to suprascapular nerve injuries. Also, type $\mathrm{V}$ and type $\mathrm{VI}$ notches with partial and completely ossified superior transverse scapular ligament respectively are more prone for suprascapular nerve entrapment. Also, that the distance between the notch and the posterior glenoid rim is lesser in type IV notch minimizing the safe zone for suprascapular surgeries[Table-2].

\section{DISCUSSION}

The present study of the types and size of the suprascapular notch provides data to diagnose and treat cases involving the suprascapular nerve. Smaller the notch, greater is the injury to the nerve. TYPE II and TYPE III suprascapular notches are more common in Indian population [Table-1].

The present study has been compared to the other studies based on Rengachery's classification.
Table 3: Comparison of the incidence of different types of notches in various other studies and the present study.

\begin{tabular}{|c|c|c|c|c|c|}
\hline $\begin{array}{c}\text { Type of the } \\
\text { notch }\end{array}$ & $\begin{array}{c}\text { Muralidhar Reddy } \\
\text { Sangam et.al [6] }\end{array}$ & $\begin{array}{c}\text { Lajja K. Sutaria } \\
\text { et.al [7] }\end{array}$ & $\begin{array}{c}\text { Usha Kannan } \\
\text { et.al [8] }\end{array}$ & $\begin{array}{c}\text { Girish v. Patil } \\
\text { et.al [9] }\end{array}$ & $\begin{array}{c}\text { Present } \\
\text { study }\end{array}$ \\
\hline TYPE I & $21.15 \%$ & $29 \%$ & $20 \%$ & $20.54 \%$ & $18.96 \%$ \\
\hline TYPE II & $8.65 \%$ & $32 \%$ & $10 \%$ & $14.29 \%$ & $34.48 \%$ \\
\hline TYPE III & $59.61 \%$ & $16 \%$ & $52 \%$ & $25 \%$ & $31.03 \%$ \\
\hline TYPE IV & $2.80 \%$ & $7 \%$ & $4 \%$ & $35.71 \%$ & $6.90 \%$ \\
\hline TYPE V & $5.76 \%$ & $7 \%$ & $4 \%$ & $1.79 \%$ & $6.90 \%$ \\
\hline TYPE VI & $1.92 \%$ & $2 \%$ & $10 \%$ & $2.68 \%$ & $3.45 \%$ \\
\hline
\end{tabular}

The incidence of the different types of notches is similar in the present study and that of Lajja KS et.al [7]. Whereas the incidence of type II notch is lesser in the studies conducted by Muralidhar et.al[6], Usha et.al[8] and Girish et al [9] [Table-3] Also, it has to be observed that the incidence of type IV notch is greater in the study by Girish et.al. In a study done in Maharashtra on 194 scapulae 9.7\% showed completely ossified superior transverse scapular ligament and partially ossified in 5.82\% [10]. All these indicate the geographical variation in the different types of suprascapular notch across the country. Hence, imaging plays an important role in evaluating cases involving the suprascapular nerve and the notch. The shape of the notch may alter the distance between it and supraglenoid tubercle which is important to determine potential safe zone to minimize iatrogenic injury of the nerve, during various surgical procedure $[6,11]$.

Table 4: Comparison of the mean STD of different types of suprascapular notches between the other study and the present study.

\begin{tabular}{|c|c|c|}
\hline $\begin{array}{c}\text { MEAN STD } \\
(\mathrm{mm})\end{array}$ & $\begin{array}{c}\text { Muralidhar Reddy } \\
\text { Sangam et.al }\end{array}$ & Present Study \\
\hline TYPE I & - & - \\
\hline TYPE II & $8.58 \pm 1.82$ & $9.68 \pm 2.5$ \\
\hline TYPE III & $10.63 \pm 3.06$ & $9.41 \pm 2.7$ \\
\hline TYPE IV & $2.64 \pm 0.68$ & $6 \pm 1.95$ \\
\hline TYPE V & $5.65 \pm 0.9$ & $9.11 \pm 2.51$ \\
\hline TYPE VI & - & - \\
\hline
\end{tabular}

Table 5: Comparison of the mean MTD of different types of suprascapular notches between the other study and the present study.

\begin{tabular}{|c|c|c|}
\hline $\begin{array}{c}\text { Mean MTD } \\
(\mathrm{mm})\end{array}$ & $\begin{array}{c}\text { Muralidhar } \\
\text { Reddy sangam } \\
\text { et. al }\end{array}$ & Present study \\
\hline Type I & - & - \\
\hline Type II & $4.73 \pm 1.45$ & $6.85 \pm 1.9$ \\
\hline Type III & $8.65 \pm 2.57$ & $6.55 \pm 1.97$ \\
\hline Type IV & $1.75 \pm 0.63$ & $3.37 \pm 0.9$ \\
\hline Type V & $7.6 \pm 1.92$ & $6.13 \pm 1.59$ \\
\hline Type VI & - & - \\
\hline
\end{tabular}


Table 6: Comparison of the mean maximum depth of different suprascapular notch between the previous study and the present study.

\begin{tabular}{|c|c|c|}
\hline $\begin{array}{c}\text { MEAN Max } \\
\text { Depth (mm) }\end{array}$ & $\begin{array}{c}\text { Muralidhar } \\
\text { Reddy sangam } \\
\text { et. al }\end{array}$ & Present study \\
\hline TYPE I & - & - \\
\hline TYPE II & $6.5 \pm 1.57$ & $4.12 \pm 1.99$ \\
\hline TYPE III & $7.11 \pm 2.41$ & $4.14 \pm 1.96$ \\
\hline TYPE IV & $2.06 \pm 0.33$ & $2.62 \pm 1.47$ \\
\hline TYPE V & $9.09 \pm 2.69$ & $4.04 \pm 1.87$ \\
\hline TYPE VI & - & - \\
\hline
\end{tabular}

The morphometric results of the present study is compared to that of the Muralidhar et.al, and the observations are not similar[Table-4,5,6]. This could be due to morphometric variations among the individuals across the country. The radiological findings of the type and size of the suprascapular notch while evaluating the cases of suprascapular nerve entrapment syndromes can be added to the present osteological study.

\section{CONCLUSION}

The movement of shoulder exerts traction on the suprascapular nerve leading to compression acquired neuropathy. Thus, the present study is helpful in determining the risk factors and diagnosing a case of suprascapular nerve palsy which can be due to ossification of superior transverse scapular ligament, traction injuries especially in sportspersons like volley ball players, tennis players, swimmers etc. So, it can be helpful in screening the population for high risks of suprascapular nerve injury especially in sports medicine. The study of the types and different measurements of the suprascapular notch provides data to arrive at a suitable diagnosis of such cases involving the suprascapular nerve as the size of the notch plays an important role. Smaller the notch, greater is the injury to the nerve. Hence the measurements are important in understanding the nerve entrapment syndrome. Also, the knowledge of different types of notches and its measurements are very helpful during the surgical decompression of the nerve and also while administering suprascapular nerve blocks for the surgeries involving the shoulder.

\section{Conflicts of Interests: None}

\section{REFERENCES}

[1]. Richard LD, Wayne VA, Adam WMM. Gray's anatomy for students. $3^{\text {rd }}$ edition. Philadelphia: Elsevier; 2015.

[2]. Post M, Mayer J. Suprascapular nerve entrapment diagnosis and treatment. Available from: https:// www.ncbi.nlm.nih.gov/pubmed/3652566. [accessed 29 ${ }^{\text {th }}$ August 2017].

[3]. Fansa H, Schneider W. Suprascapular nerve entrapment. Available from: https://www.ncbi.nlm.nih.gov /pubmed/12874724. [accessed 29 ${ }^{\text {th }}$ August 2017].

[4]. Joseph HF, Jeffrey R. Parsonage Turner syndrome. HSSJ. 2010; 6(2): 199-205. Available from: http:// www.ncbi.nlm.nih.gov/pmc/articles/PMC 2926354. [accessed 29th August 2017].

[5]. Adam LS, Schreiber, Ronnen A, Guy WF, Gerald JH. Explaining the differential of shoulder pain - Parsonage Turner syndrome. The journal of American Osteopathic association. 2009; 109: 415-22. Available from: jaoa.org/article. aspx?articleid=2093851. [accessed 29 ${ }^{\text {th }}$ August 2017].

[6]. Muralidhar RS, Sattiraju SSD, Karumachi K, Kolla A. A study on the morphology of the suprascapular notch and its distance from glenoid cavity. JCDR. 2013;7(2):189-192.

[7]. Lajja KS, Tushar VN, Sejal VP, Jadav HR, Pensi CA. Morphology and morphometric analysis of suprascapular notch. IJBAR. 2013;4(1).

[8]. Usha K, Kannan NS, Anbalagan J, Sudha R. Morphometric study of suprascapular notch in indian dry scapulae with specific reference to the incidence of completely ossified superior transverse scapular ligament. JCDR. 2014; 8(3):7-10.

[9]. Girish VP, Shishirkumar, Apoorva D, Thejeshwari, Sushanth NK. Study of morphological variations of suprascapular notch in human dry scapulae of south indians. IJSRP. 2014:4(9).

[10]. Rajeev RD, Manoj PA, Medha AD. Incidence of ossification of superior transverse suprascapular ligament of scapula in Indian population. International journal of current microbial applied sciences. 2014;3(9):1081-84.

[11]. Ritika S, Rajan S, Rajan KS, Jagdev SK, Tripta S. Suprascapular notch: A morphometric and morphologic study in north Indian population. IJAR. 2015;3(3):1306-11.

How to cite this article:

Rakshitha.C, Komala. N. SUPRASCAPULAR NOTCH IN HUMAN SCAPULA: A MORPHOMETRIC STUDY. Int J Anat Res 2018;6(1.1):4840-4843. DOI: 10.16965/ijar.2017.479 